Pacific Journal of Mathematics

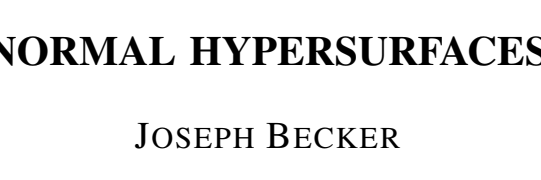




\section{NORMAL HYPERSURFACES}

\section{JOSEPH BECKER}

The purpose of this note is to give a simple analytic proof of a theorem of Oka: If $V$ is a complex analytic hypersurface whose singular locus has codimension at least two, then $V$ is normal. In other words, every weakly holomorphic function is holomorphic.

This result has since been generalized by Abhankar and Thimm to the case when $V$ is an algebraic complete intersection (which is to say that the ideal of functions holomorphic in the ambient space vanishing on $V$ is generated by $k$ functions, where $k$ is the codimension of $V$ in the ambient space).

Actually we prove a slightly stronger result than Oka's.

THEOREM. Let $V$ be a complex analytic hypersurface, $A$ a complex analytic subset of $V$ with codimension at least 2 . Then there is a bounded linear operator $\phi: \mathcal{O}(V-A) \rightarrow \mathcal{O}(V)$ such that $\phi(f) \mid V-A=f$.

Proof. Suppose $V \subset C^{n}$ and the projection $\pi: C^{n} \rightarrow C^{n-1}$ to the first $n-1$ co-ordinates gives an $r$-sheeted branched cover of $V$ in some neighborhood of the origin with branch set $B, B^{\prime}=\pi(B)$, $A^{\prime}=\pi(A)$ and $z^{\prime}=\pi(z)$. Now $\pi$ induces a homomorphism ${ }_{n-1} \mathcal{O} \rightarrow$ ${ }_{n} \mathcal{O} / I(V)=\mathscr{O}(V)$ making $\mathscr{O}(V)$ into a finitely generated $\mathscr{O}_{n-1}$ module with generators $1, z_{n}, \cdots, z_{n}^{r-1}$. Let $P\left(z^{\prime}, z_{n}\right)$ be the minimal degree polynomial for $z_{n}$ over ${ }_{n-1} \mathcal{O}$; for any $f \in \mathcal{O}(V)$ by the Weierstrass division theorem we have $f=Q P+R$ where $R \in_{n-1} \mathcal{O}\left[z_{n}\right]$ is a holomorphic polynomial of 'degree $\leqq r-1$. Hence $f$ can be written as $\sum_{i=0}^{r-1} b_{i}\left(z^{\prime}\right) z_{n}^{r-i-1} \bmod I(V)$. However the $b_{i}\left(z^{\prime}\right)$ 's are unique.

For every $z^{\prime} \notin B^{\prime}$, let $\alpha_{1}\left(z^{\prime}\right), \cdots, \alpha_{r}\left(z^{\prime}\right)$ be the values of $z_{n}$ on the fiber $\pi^{-1}(z)$ and $f_{j}=f\left(z^{\prime}, \alpha_{j}\left(z^{\prime}\right)\right)$ for $j=1, \cdots, r$. Then

$$
f_{j}=\sum_{i=0}^{r-1} b_{i}\left(z^{\prime}\right) \alpha_{j}\left(z^{\prime}\right)^{r-i-1} \text {. }
$$

These equations can be viewed as a system of $r$ linear equations in the $r$ unknowns $b_{i}\left(z^{\prime}\right)$ and solved by Cramer's rule:

$$
b_{i}\left(z^{\prime}\right)=\frac{\operatorname{det}\left[1, \alpha_{j}, \alpha_{j}^{2}, \cdots, \alpha_{j}^{r-i-2}, f_{j}, \alpha_{j}^{r-i}, \cdots, \alpha_{j}^{r-1}\right]}{\operatorname{det}\left[1, \alpha_{j}, \cdots, a_{j}^{r-1}\right]}
$$

where in both determinants the entries in the $j$ th row are indicated. The denominator is the Vandermonde determinant $\Delta\left(\alpha_{1}, \cdots, \alpha_{r}\right)$ and 
equals $\prod_{l \neq k}\left(\alpha_{l}\left(z^{\prime}\right)-\alpha_{k}\left(z^{\prime}\right)\right)$. It is an easy exercise in linear algebra to verify that the numerator equals

$$
\sum_{j=1}^{r} \sigma_{i}\left(\alpha_{1}, \cdots, \hat{\alpha}_{j}, \cdots, \alpha_{r}\right) \Delta\left(\alpha_{1}, \cdots, \hat{\alpha}_{j}, \cdots, \alpha_{r}\right) f_{j}
$$

where $\sigma_{i}$ is the elementary symmetric polynomial of degree $i$, and $\hat{\alpha}_{j}$ means that $\alpha_{j}$ is to be deleted. Therefore

$$
b_{i}\left(z^{\prime}\right)=\sum_{j=1}^{r} \frac{\sigma_{i}\left(\alpha_{1}\left(z^{\prime}\right), \cdots, \hat{\alpha}_{j}\left(z^{\prime}\right), \cdots, \alpha_{r}\left(z^{\prime}\right)\right)}{\prod_{k \neq j}\left(\alpha_{j}\left(z^{\prime}\right)-\alpha_{k}\left(z^{\prime}\right)\right)} f\left(z^{\prime}, \alpha_{j}\left(z^{\prime}\right)\right) .
$$

Since $f$ is holomorphic so is

$$
b_{i}\left(z^{\prime}\right)=\frac{1}{(r-i-1) !} \frac{\partial^{r-i-1} f}{\partial z_{n}}\left(z^{\prime}, \alpha_{j}\left(z^{\prime}\right)\right)
$$

and hence the $b_{i}\left(z^{\prime}\right)$ extend holomorphically across $B^{\prime}$. (Since $f$ and $f-Q P=R$ have the same values on $V$, it makes no difference which is used in these formulas.)

Now suppose $h \in \mathcal{O}(V-A)$, and for $z^{\prime} \notin B^{\prime}$ define

$$
\phi(h)=\sum_{j=1}^{r}\left(\prod_{k \neq j} \frac{z_{n}-\alpha_{k}\left(z^{\prime}\right)}{\alpha_{j}\left(z^{\prime}\right)-\alpha_{k}\left(z^{\prime}\right)}\right) h\left(z^{\prime}, \alpha_{j}\left(z^{\prime}\right)\right)=\sum_{i=0}^{r-1} b_{i}\left(z^{\prime}\right) z_{n}^{r-i-1}
$$

where $b_{i}$ is defined above. Then the functions are holomorphic in a neighborhood of $z^{\prime}$ provided $h$ is holomorphic near each point in $\pi^{-1}\left(z^{\prime}\right)$. Thus $b_{i}\left(z^{\prime}\right)$ extend to holomorphic functions near any point of $B^{\prime}-A^{\prime}$ and then by Hartogs' theorem, $b_{i}$ extends across $A^{\prime}$, because codim $A \geqq 2$.

The operator $\phi$ whose existence has been demonstrated is obviously linear and clearly bounded with norm one because both $\mathscr{O}(V-A)$ and $\mathscr{O}(V)$ are Fréchet spaces [3] with seminorms being sup on compact subsets; $V-A$ is dense in $V$ so $\sup _{x \in V} \mid \phi(f)=$ $\sup _{V \in x-A}|f(x)|$.

Incidentally notice that we did not use the result [4] that a function holomorphic in the complement of an analytic set of codim two is bounded in a neighborhood of that set, e.g. $\mathcal{O}(V-A)=\mathscr{O}(V)$.

REMARK. The same proof works when $\mathcal{O}(V)$ is a Cohen Macauley ring, that is the direct image sheaf of $\mathscr{O}(V)$ by a local parametrization is a free sheaf.

\section{REFERENCES}

1. S. Abhyankar, Concepts of order and rank on a complex space, and a condition for normality, Math. Ann., 141, (1960), 171-192. 
2. R. C. Gunning, Lectures on Complex Analytic Varieties, Mathematical Notes, Princeton, N.J., Princeton University Press 1970.

3. R. C. Gunning and H. Rossi, Analytic Functions of Several Complex Variables, Englewood Cliffs, N.J., Prentice-Hall 1965.

4. R. Narasimhan, Introduction to the Theory of Analytic Spaces, Lecture Notes in Mathematics 25, Berlin-Heidelberg-New York, Spring 1966.

5. K. Oka, Sur les fonctions analytique de plusieurs variables VIII, J. Math. Soc. Japan, 3 (1951).

6. W. Thimm, Untersuchungen über das Spurproblem von holomorphen Funktionen auf analytischen Mengen, 139 (1959), 95-114.

Received February 5, 1974.

Purdue University 



\section{PACIFIC JOURNAL OF MATHEMATICS}

\section{EDITORS}

RICHARD ARENS (Managing Editor) University of California

Los Angeles, California 90024

\section{R. A. BEAUMONT}

University of Washington Seattle, Washington 98105
J. DugundjI Department of Mathematics University of Southern Californı Los Angeles, California 90007

D. Gilbarg AND J. Milgram Stanford University Stanford, California 94305

\section{ASSOCIATE EDITORS}

E. F. BECKENBACH

B. H. NeUMANN

F. WOLF

K. YosHidA

\section{SUPPORTING INSTITUTIONS}

UNIVERSITY OF BRITISH COLUMBIA CALIFORNIA INSTITUTE OF TECHNOLOGY UNIVERSITY OF CALIFORNIA MONTANA STATE UNIVERSITY UNIVERSITY OF NEVADA NEW MEXICO STATE UNIVERSITY OREGON STATE UNIVERSITY UNIVERSITY OF OREGON OSAKA UNIVERSITY

\author{
UNIVERSITY OF SOUTHERN CALIFORNIA \\ STANFORD UNIVERSITY \\ UNIVERSITY OF TOKYO \\ UNIVERSITY OF UTAH \\ WASHINGTON STATE UNIVERSITY \\ UNIVERSITY OF WASHINGTON \\ AMERICAN MATHEMATICAL SOCIETY \\ NAVAL WEAPONS CENTER
}




\section{Pacific Journal of Mathematics}

\section{Vol. 61, No. $1 \quad$ November, 1975}

Jiří Adámek, V. Koubek and Věra Trnková, Sums of Boolean spaces represent every

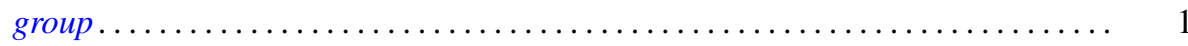

Richard Neal Ball, Full convex l-subgroups and the existence of $a^{*}$-closures of

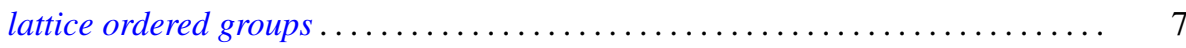

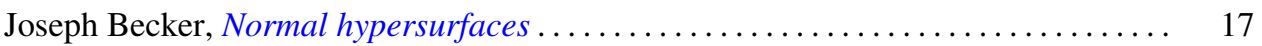

Gerald A. Beer, Starshaped sets and the Hausdorff metric . . . . . . . . . . . . . 21

Dennis Dale Berkey and Alan Cecil Lazer, Linear differential systems with

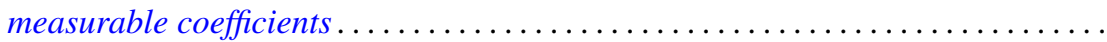

Harald Boehme, Glättungen von Abbildungen 3-dimensionaler

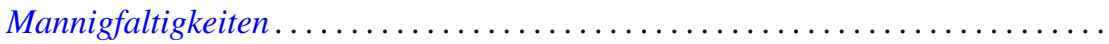

Stephen LaVern Campbell, Linear operators for which $T^{*} T$ and $T+T^{*}$

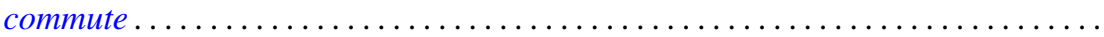

H. P. Dikshit and Arun Kumar, Absolute summability of Fourier series with

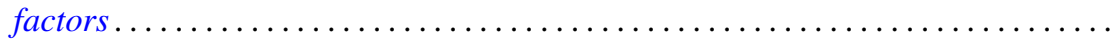

Andrew George Earnest and John Sollion Hsia, Spinor norms of local integral

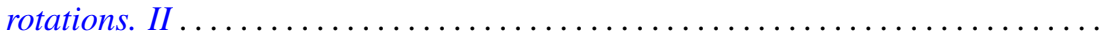

Erik Maurice Ellentuck, Semigroups, Horn sentences and isolic structures .........

Ingrid Fotino, Generalized convolution ring of arithmetic functions . . . . . . . . . . .

Michael Randy Gabel, Lower bounds on the stable range of polynomial rings .......

Fergus John Gaines, Kato-Taussky-Wielandt commutator relations and

characteristic curves

Theodore William Gamelin, The polynomial hulls of certain subsets of $C^{2}$

R. J. Gazik and Darrell Conley Kent, Coarse uniform convergence spaces. . .

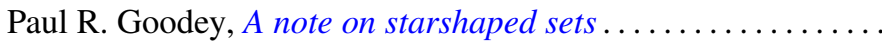

Eloise A. Hamann, On power-invariance

M. Jayachandran and M. Rajagopalan, Scattered compactification for $N \cup\{P\}$. . .

V. Karunakaran, Certain classes of regular univalent functions .

John Cronan Kieffer, A ratio limit theorem for a strongly subadditive set function in a locally compact amenable group .................

Siu Kwong Lo and Harald G. Niederreiter, Banach-Buck measure, density, and uniform distribution in rings of algebraic integers ........

Harold W. Martin, Contractibility of topological spaces onto metric spaces ....

Harold W. Martin, Local connectedness in developable spaces .

A. Meir and John W. Moon, Relations between packing and covering numbers of a tree.

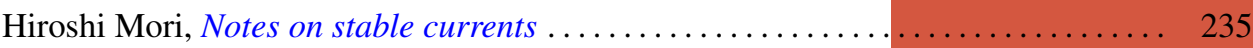

Donald J. Newman and I. J. Schoenberg, Splines and the logarithmic function . . . . 241

M. Ann Piech, Locality of the number of particles operator....

Fred Richman, The constructive theory of $K T$-modules .......

Gerard Sierksma, Carathéodory and Helly-numbers of

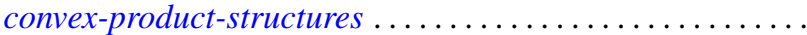

Raymond Earl Smithson, Subcontinuity for multifunctions .... . . 